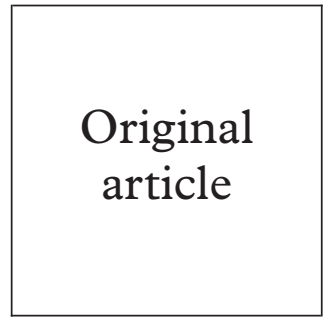

H Bradby, R Williams

\title{
Behaviours and expectations in relation to sexual intercourse among 18-20 year old Asians and non-Asians
}

Objectives: To begin to map the reported behaviours and attitudes of young Britons of south Asian origin that may have implications for sexual health. "South Asian" refers to people able to trace their ancestry from the Indian subcontinent (that is, India, Pakistan, and Bangladesh), henceforth referred to as "Asian".

Design: A cross sectional study of sexual behaviour using self report measures in a self complete section of a social survey administered by trained interviewers in 1996 .

Setting: Greater Glasgow, Scotland.

Subjects: Sample ( $\mathrm{n}=824$ ) originally recruited aged $14-15$ in 1992 in secondary schools in Greater Glasgow and subsequently traced through general practitioner registration for 1996 survey. 492 Asians and non-Asians aged 18-20 years old eventually interviewed in their own homes. Main outcome measures: Self reported experience of sexual intercourse, age at first intercourse, and contraceptive practice over year before interview.

Methods: Measures of sexual behaviour and attitudes were elicited through a self complete questionnaire filled out in the presence of, and returned to, a trained social interviewer.

Results: Asians, and particularly Asian women, were far less likely to report having had heterosexual intercourse. Those Asian women who had had intercourse were likely to do so for the first time at an older age, and with an older partner, than the non-Asian women. Asian women were less likely to report using the pill than non-Asian women, irrespective of their marital status, and Asian men were less likely than non-Asian men to report using condoms. Asian sexual abstinence was reported to be for religious reasons, which were not important for non-Asians. In contrast with non-Asians, Asians saw themselves as likely to be married with children within the next 5 years. Asian men considered the ideal age to marry for men and women to be younger than the non-Asian men's average estimate. Asian and non-Asian women suggested a similar ideal age for men to marry, but Asian women considered a younger age appropriate for women than did nonAsian women.

Conclusions: The higher level of sexual abstinence among Asians, and particularly women, has implications for the delivery of sexual health services to the minority who are sexually active before marriage. The underreporting of condom use by Asian men compared with their non-Asian counterparts, suggests a failure of the existing sexual health education and health services to reach minority ethnic young men which may be remedied by collaborative work with institutions currently used by the Asian community. (Sex Transm Inf 1999;75:162-167)

Keywords: ethnicity; British Asian; sexual behaviour; young people

\section{Introduction}

Likelihood of infection with gonorrhoea has been found to vary with social class, age, and ethnicity in two British cities, ${ }^{12}$ and reported cases of AIDS vary with ethnicity. ${ }^{3}$ For both of these infections people of south Asian origin (that is those able to trace their ancestry from the Indian subcontinent-India, Pakistan, and Bangladesh, henceforth referred to as "Asians"), have much lower rates of infection than other ethnic groups. One reason for these low rates of infection might be the late age of first intercourse compared with other ethnic groups. A median age at first intercourse of 18 has been reported for "white" men and women, 20 for Asian men, and 21 for Asian women in the British National Survey of Sexual Attitudes and Lifestyles (NATSAL). ${ }^{4}$ Later age of first intercourse correlates with a smaller lifetime number of sexual partners, and therefore a reduced risk of STIs (sexually transmitted infections). ${ }^{4}$

Beyond the finding of later age of first intercourse of Asians, we have little insight into the social epidemiology of sexual behaviour in any ethnic group of south Asian origin. However devotion of resources to the discovery of the protective mechanism(s) may mean that measures which help maintain the low rate of infection can be developed.

A further reason for examining the sexual health of Asians in Britain is the future possibility of the transmission of HIV from the Indian subcontinent. India is experiencing an epidemic of HIV transmission in high risk populations, especially commercial sex workers, ${ }^{5}$ and, although data sources are incomplete and limited, ${ }^{6}$ there is evidence that HIV prevalence is increasing among monogamous married women, with no history of sex work, previously thought to be low risk in 
India. ${ }^{78}$ There is no evidence as to whether carriers of HIV are also migrants, but it would be wise to establish an understanding of the sexual norms of those most likely to be in sexual contact with potential carriers, particularly in the light of the importance of migration in HIV spread elsewhere. ${ }^{9} 10$

British Asians are good candidates for preventative services as they use general practitioner services as much as or more than other ethnic groups. ${ }^{11}$ However, women (aged 16-74) of south Asian origin, particularly those of Pakistani and Bangladeshi origin, have lower levels of uptake of cervical screening compared with other ethnic groups, ${ }^{3}$ and a smaller proportion of Asian women use contraception than any other ethnic group. ${ }^{3}$ One reason given by south Asian women for not having smear tests was a lack of knowledge about the test. ${ }^{12}$ Other research has confirmed the low level of knowledge about breast and cervical cancer and screening, ${ }^{13}$ such that low uptake does not apparently constitute a considered rejection of the service. Underuse of "family planning" services by Asian women is confirmed by a small local study, which also noted a total absence of unmarried Asian women service users. ${ }^{14}$

The political and practical difficulties of sex research with any social group, and the particular difficulties involved with ethnic minorities, stemming from previous racist health research ${ }^{15}{ }^{16}$ and racist, sexist stereotypes with regard to sexual behaviour, ${ }^{17-19}$ have meant that researchers in Britain have rarely tried to question Asians about their sexual behaviour. On the occasions when it has been attempted, it has sometimes met such reluctance that the resulting data have been unpublishable. ${ }^{12}$

The difficulties of Asians talking about sex, and their apparent sexual modesty have been assumed to be enforced by the authority of religious leaders and elders. Muslim, Sikh, and Hindu groups have secular and theological traditions which place great emphasis on modest behaviour, and on sexual activity being confined to marriage. ${ }^{20}$ These traditions are enforced by sanctions that are particularly stringently applied to women who disregard norms of behaviour. ${ }^{21-23}$ However, qualitative research has shown that young Asian women are challenging the basis (although not necessarily the specifics) of some prohibitions on their conduct, on the grounds that they have little or no theological justification. ${ }^{23}$ Survey work suggests that the British born generation of Asians are more willing to talk about sex than their migrant forbears. ${ }^{12}$ Asking young Asians about the motivations behind their sexual behaviour is overdue, particularly given the attention paid to that of other ethnic groups in Britain.

This paper reports on a survey of second generation Asians and non-Asians, aged 18 20.

The research questions addressed are:

(1) Can previous findings of a delayed experience of first intercourse of Asian men and women, compared with the non-Asian population, be confirmed, and does this result in a smaller number of sexual partners?

(2) Among the sexually active Asian men and women, are the same proportions using the condom and the pill as in the non-Asian population?

(3) Among those people who are choosing not to have sex, what role do considerations of marriage, childbearing, religion, health, and family approval play?

(4) What are the implications of these findings for sexual health policy?

\section{Methods}

The data presented come from a social survey in Glasgow, conducted in 1996, which was a follow up at home of a survey based in secondary schools in the Greater Glasgow area, of 824 14 and 15 year olds in $1992 .{ }^{24}$ The original sample targeted the 12 secondary schools in Glasgow city with $2 \%$ or more pupils who were Muslim, Sikh, or Hindu. Two of these schools, with the smallest number of south Asian pupils, were used as pilot schools, one could not accommodate the survey within the field work period and the remaining nine were included in the study. These nine with the pilot schools covered $94 \%$ of Muslim, Sikh, and Hindu pupils recorded by the education department in 1991. All pupils with south Asian names in their third and fourth year at secondary school were included in the target sample. A proportionate random sample of pupils in the same years who did not have south Asian names was selected, giving a general population, non-Asian sample. ${ }^{24}$ The follow up sample targeted the total original sample with an initial mailing which included a prepaid postcard that could be used to opt out.

Where young people or their relatives had not opted out but seemed reluctant to take part, interviewers who spoke the appropriate languages were available to negotiate access. The interviews lasted between 45 minutes and 3 hours, with the majority lasting between 1 and 2 hours.

A brief self complete questionnaire concerning sexual and contraceptive experience was filled out by the respondent during the interview, and returned to the interviewer in a sealed envelope. This included questions on most recent intercourse (defined as "vaginal intercourse, oral sex, and anal sex"), age and partner's age at first intercourse, use of contraceptives, and homosexual behaviour. There were no face to face questions about sexual practice or abstinence in the interview schedule, although respondents occasionally re-

Table 1 Proportion of unweighted 1992 sample at 1996 sweep

\begin{tabular}{lcc}
\hline & $\%$ & Unweighted $n$ \\
\hline $\begin{array}{l}\text { Completed interview } \\
\text { Refused face to face or opted out }\end{array}$ & 60 & 492 \\
$\quad$ by postcard & 21 & 175 \\
Non-contact & 12 & 96 \\
Confirmed as moving away from & & \\
$\quad 1992$ address & 7 & 59 \\
Deceased & 0 & 2 \\
Total & 100 & 824 \\
\hline
\end{tabular}


Table 2 Proportion of weighted sample by sex and ethnicity

\begin{tabular}{lrrrr}
\hline & Asian & Non-Asian & Total & $\begin{array}{l}\text { Missing } \\
\text { observations }\end{array}$ \\
\hline Sex & & & & \\
$\quad$ Men & 50 & 42 & & \\
$\quad$ Women & 50 & 58 & & \\
$\quad$ Weighted n) & $(202)$ & $(187)$ & $(389)$ & 0 \\
Religion & 79 & 0 & & \\
$\quad$ Muslim & 14 & 0 & & \\
Sikh/Hindu & 7 & 84 & & \\
$\begin{array}{l}\text { Other (mainly } \\
\text { Christian) }\end{array}$ & 0 & 16 & & \\
$\quad \begin{array}{l}\text { No religion } \\
\text { (Weighted n) }\end{array}$ & $(203)$ & $(172)$ & (375) & 13 \\
\hline
\end{tabular}

Table 3 Percentage of all men and women who reported having had intercourse with someone of the opposite sex by ethnicity

\begin{tabular}{lcc}
\hline & Asian & Non-Asian \\
\hline Sexually experienced men & 44 & $77^{\star \star \star}$ \\
Sexually experienced women & 25 & $83^{\star \star \star}$ \\
Sexually experienced and unmarried women & 11 & $83^{\star \star \star}$ \\
(Weighted n) & $(202)$ & $(187)$
\end{tabular}

Significance of Asian-non Asian difference: ${ }^{\star} \mathrm{p}<0.05,{ }^{\star \star} \mathrm{p}<0.01$, $\star \star \star \mathrm{p}<0.001, \mathrm{~ns}=$ non-significant.

quested help with the self complete questionnaire from the interviewer.

Data analysis was carried out with sPSs for windows. $\chi^{2}$ tests and comparison of means were used to assess the significance of differences between Asian and non-Asian men and women.

\section{Results}

RESPONSE RATES AND BIAS

Table 1 shows a breakdown of those individuals lost from the 1992 sample by 1996 . There was no evidence of selection bias in the 1996 sample in terms of sex, age, ethnicity, education, employment, parents' employment, health behaviours, health outcomes, or morbidity, as reported in $1992 .{ }^{25}$ The only significant instance of selection out of 43 variables tested, was a slightly lower proportion from the Sikh and Hindu minority $(14 \%$ v $16 \%$ ) retained from the 1992 sample. There is no reason to believe this is relevant for the Asian versus non-Asian comparisons presented in this article.

There were four people who refused to complete the sexual health section of the questionnaire and three who left all the questions blank, and all these were men. Of the seven, two were Muslims, two were Sikhs, one was Roman Catholic, and the other two reported no religion for themselves or their parents in 1992 or 1996.

\section{CONVENTIONS IN TABLES}

The 1992 sample was weighted to correct for differential sampling and response $\mathrm{e}^{24}$ and these weights were reapplied to the 1996 data set. All the tables, except table 1, show weighted data and the totals are subject to rounding errors of plus or minus 1 .

\section{DESCRIPTION OF TABLES}

Table 2 shows that the sample was evenly split between men and women and Asians and nonAsians. The majority of the Asian sample was Muslim (79\%) with a minority of Sikhs and
Hindus (14\%). The majority of the non-Asian sample were Christian (99\%), although this does not imply that they all reported regular religious observance. The majority of the Asians (86\%) and the non-Asians (96\%) were British born (not shown). As a proxy for standard of living we asked about parents' ownership of a list of eight consumer durables (telephone, washer-drier, video recorder, CD player, cassette player, home computer (PC), microwave oven, central heating), and found no difference in the mean number owned by Asians and non-Asians (not shown).

The proportion of Asians who reported heterosexual intercourse was much smaller than the non-Asians (table 3). All except for 17 of the sexually experienced Asians were unmarried. One of the married 17 was an Asian man, and the rest were Asian women and all reported experience of intercourse. When married women are excluded, a very small minority of unmarried Asian women reported having experienced intercourse.

The mean age at first intercourse of men did not vary with ethnicity, but Asian women were on average a year older than the non-Asian women (table 4). This pattern is replicated in comparing the mean age of young people's partner at first intercourse: there is no significant difference between Asian and nonAsian men's partners (table 4), but Asian women's partners were $2 \frac{1}{2}$ years older (on average) than non-Asian women's. Asian women have had, on average, fewer partners than non-Asian women, but there is no difference between Asian and non-Asian men. The NATSAL sample covered $16-59$ years and so, for comparative purposes, consider table 5

Table 4 Comparison of mean age at first sexual intercourse of men and women and their partners, and total number of sexual partners to date, by ethnicity

\begin{tabular}{lrrr}
\hline & Asian & Non-Asian & \\
\hline Men & & & \\
Mean age (years) & 16.20 & 16.04 & ns \\
Standard deviation & 1.70 & 1.49 & \\
Partner's mean age & 17.73 & 16.98 & ns \\
Standard deviation & 3.40 & 2.02 & \\
Mean number of partners & 5.10 & 5.67 & ns \\
Standard deviation & 6.57 & 6.03 & \\
Median number of partners & 3.00 & 4.00 & \\
Range & 34.00 & 34.00 & \\
Women & & & \\
Mean age (years) & 17.46 & 16.48 & $\star \star$ \\
Standard deviation & 1.36 & 1.20 & \\
Partner's mean age & 21.31 & 18.81 & $\star \star \star$ \\
Standard deviation & 2.81 & 2.98 & \\
Mean number of partners & 1.45 & 4.00 & $\star$ \\
Standard deviation & 0.88 & 5.79 & \\
Median number of partners & 1.00 & 2.00 & \\
Range & 3.00 & 39.00 & \\
\hline
\end{tabular}

Significance of Asian-non Asian difference: ${ }^{\star} \mathrm{p}<0.05,{ }^{\star \star} \mathrm{p}<0.01$, $\star \star \star \mathrm{p}<0.001, \mathrm{~ns}=$ non-significant.

Table 5 Comparison of percentages of Asians and non-Asian men and women who reported having experienced sexual intercourse by the age of 16

\begin{tabular}{lccc}
\hline & Asian & Non-Asian & \\
\hline Men & 54 & 60 & $\mathrm{~ns}$ \\
(Weighted n) & $(41)$ & $(60)$ & \\
Women & 19 & 48 & $\star \star$ \\
(Weighted n) & $(26)$ & $(90)$ &
\end{tabular}

Significance of Asian-non Asian difference: ${ }^{\star} \mathrm{p}<0.05,{ }^{\star \star} \mathrm{p}<0.01$, $\star \star \star \mathrm{p}<0.001, \mathrm{~ns}=$ non-significant. 
which presents the proportions of Asian men and women who experienced sexual intercourse by age 16. Significantly fewer Asian women compared with non-Asian women were sexually experienced by 16 , but there was no difference for men.

Among those men who had experienced sexual intercourse, Asians were less likely than non-Asians to report using the three most popular contraceptive methods during the previous year, although this difference was only significant for the condom and withdrawal (table 6). A logistic regression of the relation between ethnicity and condom use in which the total number of partners was taken into account showed no difference in these results (not shown). Among women the pattern was the same, but only Asian women's lower reported levels of pill use, compared with nonAsian women, was significant. The significance of this result remains when married women are excluded, despite the small numbers involved.

Table 7 shows the numbers of men and women who cited various reasons for never having experienced sexual intercourse. The list from which respondents chose reasons that applied to them included the following statements: (1) religious reasons $(61 \%)$; (2) I want to meet the right woman/man before having sex $(47 \%)$; (3) I want to wait until I'm older before having sex (31\%); (4) family disapproval (21\%); (5) I want to avoid HIV (18\%); (6) I want to avoid sexually transmitted diseases $(17 \%)$.

Only the frequency with which Asians referred to religion distinguished them from

Table 6 Percentage of sexually active men and women who reported the use of various contraceptive methods in the previous year, by ethnicity

\begin{tabular}{lccc}
\hline \multicolumn{3}{c}{ Asian } & Non-Asian \\
\hline Men's reported contraception & & & \\
$\quad$ Pill & 32 & 54 & $\mathrm{~ns}$ \\
Condom & 63 & 84 & $\star$ \\
Withdrawal & 5 & 14 & $\star$ \\
$\quad($ Weighted n) & $(41)$ & $(57)$ & \\
Women's reported contraception & & \\
$\quad$ Pill & 38 & 76 & $\star \star \star$ \\
Condom & 60 & 74 & $\mathrm{~ns}$ \\
Withdrawal & 4 & 17 & $\mathrm{~ns}$ \\
(Weighted n) & $(25)$ & $(87)$ & \\
Unmarried women's contraception & & \\
Pill & 33 & 76 & $\star \star$ \\
Condom & 78 & 74 & $\mathrm{~ns}$ \\
Withdrawal & 0 & 17 & $\mathrm{~ns}$ \\
(Weighted n) & $(9)$ & $(87)$ & \\
\end{tabular}

Significance of Asian-non Asian difference: ${ }^{\star} \mathrm{p}<0.05,{ }^{\star \star} \mathrm{p}<0.01$ $\star \star \star \mathrm{p}<0.001, \mathrm{~ns}=$ non-significant.

Table 7 Percentage of sexually inexperienced men and women who reported various reasons for sexual abstinence, by ethnicity

\begin{tabular}{lccl}
\hline & Asian & Non-Asian & \\
\hline Men's reported reasons & & & \\
$\quad$ Religious & 59 & 6 & $\star \star \star$ \\
Right woman & 38 & 47 & $\mathrm{~ns}$ \\
$\quad$ Family disapproval & 14 & 6 & $\mathrm{~ns}$ \\
Women's reported reasons & & & \\
$\quad$ Religious & 83 & 33 & $\star \star \star$ \\
Right man & 46 & 78 & $\mathrm{~ns}$ \\
Family disapproval & 27 & 28 & $\mathrm{~ns}$ \\
(Weighted n) & $(127)$ & $(35)$ &
\end{tabular}

Significance of Asian-non Asian difference: ${ }^{\star} \mathrm{p}<0.05,{ }^{\star \star} \mathrm{p}<0.01$, $\star \star \star \mathrm{p}<0.001, \mathrm{~ns}=$ non-significant.
Table 8 Percentage of women and men who reported belonging to a religious group, the importance of religion, anticipation of marriage, cohabitation, and childbearing by ethnicity

\begin{tabular}{|c|c|c|c|c|}
\hline \multirow[b]{2}{*}{ Factorst } & \multicolumn{2}{|l|}{ Men } & \multicolumn{2}{|c|}{ Women } \\
\hline & Asian & Non-Asian & Asian & Non-Asia \\
\hline $\begin{array}{l}1 \text { Belong to a religious } \\
\text { group }\end{array}$ & 92 & $35^{\star \star \star}$ & 77 & $39^{\star \star \star \star}$ \\
\hline $\begin{array}{l}2 \text { Religion quite/very } \\
\text { important }\end{array}$ & 96 & $43^{\star \star \star \star}$ & 97 & $51^{\star \star \star \star}$ \\
\hline $\begin{array}{l}\text { 3a Quite/very likely to } \\
\text { be married }\end{array}$ & 63 & $27^{\star \star \star}$ & 77 & $39^{\star \star \star}$ \\
\hline $\begin{array}{l}\text { 3b Quite/very likely to } \\
\text { have kids }\end{array}$ & 39 & $16^{\star \star}$ & 46 & $31^{\star \star}$ \\
\hline $\begin{array}{l}\text { 3c Very/quite likely to } \\
\text { cohabit }\end{array}$ & 24 & $62^{\star \star \star}$ & 6 & $69^{\star \star \star}$ \\
\hline Weighted n & 101 & 78 & 101 & 109 \\
\hline
\end{tabular}

Significance of Asian-non Asian difference: ${ }^{\star} \mathrm{p}<0.05,{ }^{\star \star} \mathrm{p}<0.01$, $\star \star \star \star \mathrm{p}<0.001, \mathrm{~ns}=$ non-significant.

$\dagger 1$ Do you belong to a religious group or church?

2 How important is religion in your life? Is it ...(a) very important, (b) quite important, (c) not very important, (d) not at all important?

3 Finally, what do you think you might be doing in 5 years time? Please tell me how likely it is that the following will have happened to you by the year 2001: (a) to be married, (b) to have (more) children, (c) to be unmarried but living with someonevery unlikely, quite unlikely, quite likely, very likely.

Table 9 Comparison of mean ideal age in years for men and women to marry by sex and ethnicity

\begin{tabular}{lrrr}
\hline & Asian & Non-Asian & \\
\hline Men & & & \\
$\quad$ ideal age for men & & & \\
$\quad$ mean & 24.46 & 25.55 & \\
$\quad$ standard deviation & 2.48 & 2.87 & \\
ideal age for women & & & \\
$\quad$ mean & 22.95 & 25.14 & \\
$\quad$ standard deviation & 2.34 & 2.64 & \\
Women & & & \\
ideal age for men & & & \\
$\quad$ mean & 25.45 & 25.65 & \\
$\quad$ standard deviation & 2.11 & 3.23 & \\
ideal age for women & 23.61 & 24.87 & \\
$\quad$ mean & 2.14 & 2.12 & \\
$\quad$ standard deviation & & \\
\hline
\end{tabular}

Significance of Asian-non Asian difference: ${ }^{\star} \mathrm{p}<0.05,{ }^{\star \star} \mathrm{p}<0.01$, $\star \star \star \mathrm{p}<0.001, \mathrm{~ns}=$ non-significant.

the non-Asians on this count. Citing religion as a reason for celibate behaviour was consonant with other, more general, indicators of the importance of religion. Asians were more likely than non-Asians to say they belonged to a religious group, and to report that religion was important in their lives (table 8).

Asians were more likely than non-Asians to view marriage, and child bearing, to be a feature of their lives during the next 5 years, and by contrast non-Asians were more likely than Asians to think they would be unmarried but cohabiting with someone within 5 years. The prospect of imminent marriage was reflected in young people's assessments of the ideal age for marriage. There were no significant differences by ethnicity in the age that women considered appropriate for men to marry, both ethnic groups agreeing on a figure of just over 25 years (table 9). Asian women suggested a younger ideal age of marriage for women than non-Asian women. Asian men considered that both men and women should marry at a younger age than non-Asian men considered appropriate. 


\section{Discussion}

The NATSAL finding of delayed age at first intercourse was confirmed for Asian women but not Asian men. However, $77 \%$ of the nonAsian men had experienced intercourse by only $44 \%$ of the Asians; hence, when the sample is older and closer to the mean age of the NATSAL sample a difference in age at first intercourse may emerge from those not currently experienced. Delayed first intercourse should result in a smaller lifetime total number of partners (which is apparent for the Asian women in this sample at this age), and therefore a lower risk of STIs. However, this reduced risk also depends on the sexual behaviour of their partners. Within the Asian group the experience of sexual intercourse was far less common among women than among men, with unmarried Asian men being four times more likely to have experienced intercourse than unmarried Asian women. This sex related pattern in sexual experience has been found in other Asian populations. ${ }^{26}$ Those Asian women who had experienced intercourse were on average significantly older on the first occasion than the non-Asian women, and this gap is set to increase, as a minority of Asian women had experienced intercourse (25\%) compared with a majority of non-Asian women (83\%). Asian women's partners were older than non-Asian women's at the time of the women's (though not necessarily the partners') first intercourse. The greater age gap probably means that Asian women's partners have had more previous sexual partners, as the number of lifetime partners can only increase with age.

A smaller proportion of sexually active Asian men reported using condoms compared with non-Asian men and a smaller proportion of Asian women reported using the contraceptive pill, whether or not married women (who were all Asian) were excluded. Some Asian women's risk of STIs will be increased by their partners' behaviour. On the evidence of in-marrying among Asians, ${ }^{27}$ the Asian women in this sample are likely to marry Asian men similar to those in this sample, and these men report low use of prophylactics. Given the small number (nine) of Asian women who reported premarital sexual activity, most of whom reported only one sexual partner ever, it is likely to be non-Asian women who are the premarital sexual partners of almost all of the Asian men in this sample, particularly given that the study included a near total sample of Asians of this age group in the Glasgow city area.

Asians are more likely than non-Asians to cite religion as a reason for celibacy and also to see married life with children as an imminent prospect. Non-Asian women had experienced coitarche almost universally, but did not expect marriage or child bearing in the next 5 years. The majority of Asian women who reported having had sexual intercourse were married. More Asian women (and men) also anticipated marriage and child bearing within the next 5 years than non-Asians. Therefore, delayed first intercourse is combined with the expectation of marriage in the near future, from which pregnancy is anticipated. The lower levels of contraceptive practice among Asian women, compared with non-Asian women, may be due to the anticipation that childbearing will follow marriage. This explanation is not valid for Asian men's lower reported use of condoms because only one of them was married.

The evidence from this study is that young Asians attribute their sexual abstinence more to religious reasons, than to health reasons, avoidance of pregnancy, family pressure, or not having yet met the right partner. Non-Asians very rarely reported religion to be a reason for sexual abstinence. More generally young Asians reported religion to be an important feature of their lives, unlike the non-Asians. While religious motivation makes it likely that current low levels of early sexual activity will persist, it also means that the minority of young people who are sexually active may find it difficult to find support and advice if many of their family and peers disapprove of such behaviour.

There are, of course, limitations to the conclusions that can be drawn from this study. The questions about sexual health did not include any information on the characteristics of the sexual partners beyond their age, nor did they cover any previous diagnoses of STIs or use of sexual health services of the respondent or his/her partner. When using comparisons as crude as "Asian" and "non-Asian", the possible heterogeneity of sexual behaviour that is being masked within the groups must be acknowledged. Our ethnographic work with the overwhelmingly Punjabi Asian community in Glasgow suggests that there are important similarities between the Muslim and nonMuslim groups because of their common Punjabi origins such that there may be less hetereogeneity than in other British cities.

The findings have implications for advice offered to young Asians on their first contact with the sexual health services. Firstly, it clearly cannot be assumed by service providers that Asian men or women have been celibate before marriage, nor that safer sex barrier methods have been employed with previous partners. Therefore, Asians, like other users of "family planning" services, should be advised of the benefits of condom use for the prevention of the spread of infections. It is particularly important that this message is communicated to young men, as their sexual activity is greater than the Asian women to whom they may eventually be married, and their condom use is lower than non-Asian men. Secondly, the expectations of premarital and marital sexual activity differ between Asians and non-Asians, in terms of an expectation of earlier marriage, followed by child bearing. So although no assumptions should be made about Asians' sexual behaviour, the community's health service needs are likely to differ from their non-Asian peers.

It would seem that sexual health services, certainly in the Glasgow locality, need to undertake some public relations work in making themselves known about and relevant to young Asians, both married and unmarried, but particularly single men. Collaboration of sexual health services with institutions that 
have good relations with local Asians, such as schools, general practices, and community groups could help to make sexual health services more accessible to a broader range of minority ethnic groups. A priority must be to encourage condom use among young men, which could safeguard the future sexual health of the whole community and, in particular, the fertility of their future wives, which could be compromised by common STIs such as chlamydia. Fertility in married life is important to most ethnic groups, but arguably this is particularly so for Asians.

Contributors: HB designed the survey schedule, managed the survey, and wrote the paper; RW supervised the study and revised the paper.

The authors are supported by the Medical Research Council and are grateful for the comments of their colleagues Geoff Der, Graham Hart, Helen Sweeting, Daniel White, and from anonymous referees on previous drafts of this article.

1 Lacey CJN, Merrick DW, Bensley DC, et al. Analysis of sociodemography of gonorrhoea in Leeds, 1989-93. BMY 1997:314:1715-18.

2 Low N, Daker-White G, Barlow D, et al. Gonorrhoea in inner London: results of a cross sectional study. BMF 1997; 314:1719-23.

3 Church J, Summerfield C, eds. Social focus on ethnic minorities. London: Stationery Office, 1996

4 Johnson AM, Wadsworth J, Wellings K, et al. Sexual attitudes and lifestyles. Oxford: Blackwell Scientific Publications, 1994.

5 Bollinger RC, Tripathy SP, Quinn TC. The human immunodeficiency virus epidemic in India. Current magnitude and future projections. Medicine 1995;74:97106.

6 Jain MK, John J, Keush GT. A review of human immunodeficiency virus infection in India. $\mathcal{F}$ Acquir Immune Defic Synd 1994;7:1185-94.

7 Gangakhedkar RR, Bentley ME, Divekar AD, et al. Spread of HIV infection in married monogamous women in India. of HIV infection in married

8 Rodrigues JJ, Mehendale SM, Shepherd ME, et al. Risk factors for HIV infection in people attending clinics for sexually transmitted diseases in India. BMF 1995;311:283-6.
9 Brewer TH, Hasbun J, Ryan CA, et al. Migration, ethnicity and environment: HIV risk factors for women on the sugar cane plantations of the Dominican Republic. AIDS 1998;12:1879-87.

10 Decosas J, Kane F, Anarfi J, et al. Migration and AIDS. Lancet 1995;346:826-8.

11 Smaje C, Le Grand J. Ethnicity, equity and the use of health services in the British NHS. Soc Sci Med 1997;45:485-96.

12 Rudat K. Black and minority ethnic groups in England. London: Health Education Authority, 1994.

13 Kernohan E. Evaluation of a pilot study for breast and cervical cancer screening with Bradford's minority ethnic women; a community development approach, 1991-93. $B r$ 7 Cancer 1996;74(Suppl XXIX):S42-6.

14 Baraitser P. Family planning and sexual health: understanding the needs of South Asian women in Glasgow. Fournal of Ethnic and Migration Studies 1999;25:133-49.

15 Bhopal R. Is research into ethnicity and health racist, unsound, or important science? BMF 1997;314:1751-6.

16 Jones J. Bad blood. New York: Free Press, 1981.

17 Ballhatchet K. Race, sex and class under the Raj. Imperial attitudes and policies and their critics, 1793-1905. London: Weidenfeld and Nicolson, 1980.

18 Miles R. Racism. London: Routledge, 1989.

19 Barkan E. The retreat of scientific racism: changing concepts of race in Britain and the United States between the world wars. Cambridge: Cambridge University Press, 1992.

20 Thomson R, ed. Religion, ethnicity and sex education: exploring the issues. London: National Children's Bureau, 1993.

21 Bhachu P. Twice migrants-East African settlers in Britain. London: Tavistock, 1985.

22 Shaw A. A Pakistani community in Britain. Oxford: Blackwells, 1988.

23 Bradby H. Negotiating marriage: young Punjabi women's assessment of their individual and family interests. In Barot R, Bradley H, Fenton S, eds. Ethnicity, gender and social change. London: Macmillan, 1999.

24 Shams M, Williams R. Health and health behaviours among Glasgow 14-15 year olds of South Asian and other background. MRC Medical Sociology Unit Working Paper. Glasgow: MRC Medical Sociology Unit, 1993.

25 Bradby H, Williams R. Health and health behaviour among Glasgow 18-20 year olds of South Asian and non-Asian background: A follow up. MRC Medical Sociology Unit Working Paper. Glasgow: MRC Medical Sociology Unit, 1998.

26 Mathai R, Ross M, Hira S. Concomitants of HIV/STD risk behaviours and intention to engage in risk behaviours in adolescents in India. AIDS Care 1997;9:563-76.

27 Modood T, Berthoud R, Lakey J, et al. Ethnic minorities in Britain. London: Policy Studies Institute, 1997. 